\title{
Let us entertain you
}

\section{No one likes waiting, especially for dental or medical treatment, so how can we best keep our patients entertained? Stephen Hancocks considers.}

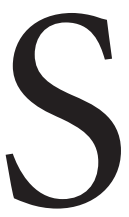

ome dental management gurus insist that the waiting room shouldn't be called a waiting room at all since the very use of the word implies delay and poor organisation, not to mention grubby connotations of aged railway stations with draughty windows and nasty smells. Terms such as 'reception facility' or 'client lounge' are the preferred customer care speak designations but in the real world, the space allocated to where people wait is most usually called, well, the waiting room.

Of course no one is ever kept waiting on purpose and indeed everything is done to make sure that the through-put of folk is as efficient as possible. However, there are times when with the best organisation in the world life has a habit of throwing an unexpected wobbly. Little Johnny takes a nose dive in the playground and needs his newly erupted incisors treated for trauma and splinted a bit rapidly - delay! Mrs Gundle's dentures take far longer to fit and adjust than anyone could have foreseen; and $\mathrm{Mr}$ Chairspeak's habit of fainting holds the whole afternoon's schedule up by a full quarter hour. Heck! Quite apart from which, patients do on occasion turn up way ahead of their appointment time, the upshot of all of which means that waiting is required.

So it is at times like these that keeping the patients happy comes into the frame. Explanations are mandatory nowadays as best practice but also provide the opening in which to mention the plethora of optional sources of entertainment that you have laid on for their

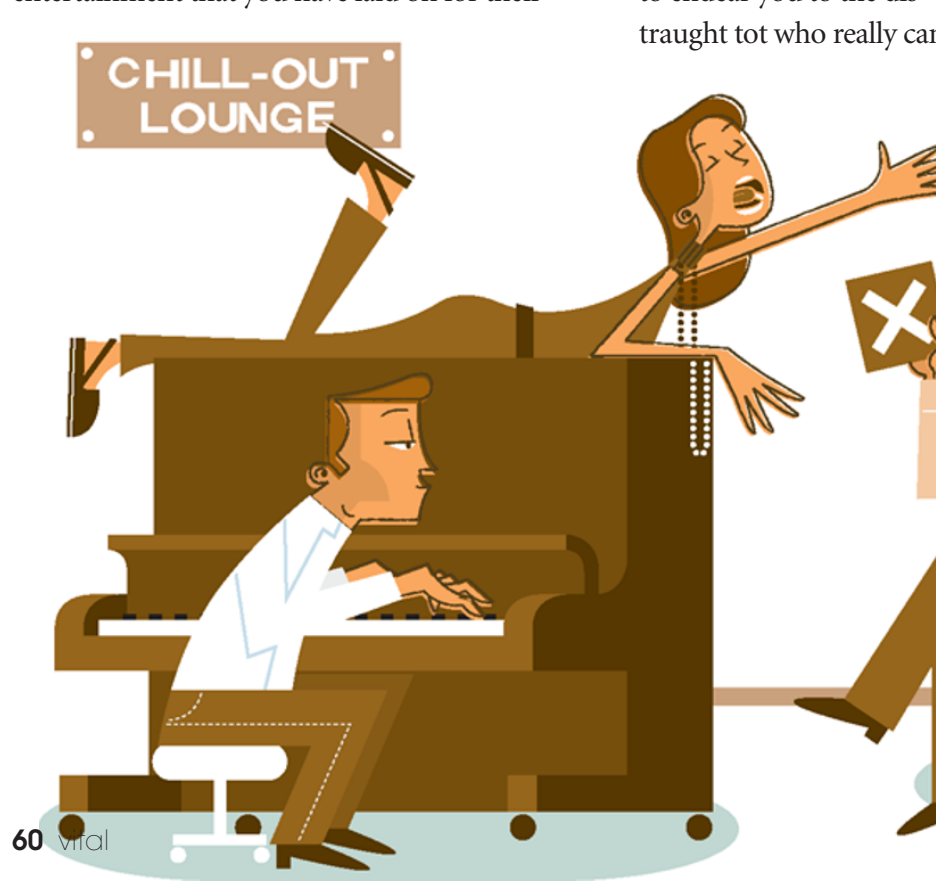

pleasure, amusement, education and distraction.

The good old stand-by is of course the magazine. A classic of well-thumbed tradition, the crumpled copy of Country Life or Hello says more about the practice than acres of customerspeak ever can; as does Auto Trader, Busy Fingers Knitting Patterns, Kung Fu Monthly and Traction Engine Enthusiast.

\section{'You could do worse}

\section{than get together}

\section{a practice quartet

$$
\text { to do requests.' }
$$

Television is a more recent addition and this can take on a whole raft of new possibilities. For example, it is possible to have the regular scheduled programmes playing throughout the day. The trouble is that the programmes don't always end at the same time that the patient is called in to the surgery. Most adults can understand the need to tear themselves away from the screen even if it does mean missing the crucial scene in which the murderer is unmasked, the denouement when the plot is revealed or worse still, a crucial ingredient for a dish under preparation in a celebrity kitchen. Not so for our younger charges. Being forcibly evicted when the episode of Bob the Builder is in full swing is hardly likely to endear you to the distraught tot who really can't grasp the need to go anywhere else until the familiar closing music comes on.

Being at the mercy of the schedules also means that you can't immediately control what is on, which might be singularly inappropriate. A re-run of Sweeney Todd may not be entirely conducive to putting your new patient into the right frame of mind but even relatively benign daytime offerings can include the gory, the slightly grizzly and the downright yukky. Which leads us neatly on to the more controllable option of continuous loop videos or DVDs. The trouble here is that the notion of education rears its unwelcome head. Strange as it may seem (especially to dentists) not all patients want to watch crownpreps being cut, rubber dams being applied or implants screwed down. Sometimes beautiful footage of walks in Cumbria is the only thing to take one's mind off the current waiting situation.

Music too can be a great calming influence but the difficulty here comes in trying to be too many things to too many different people. While Handel is just what the doctor ordered for some, Status Quo fans find it just a tad er, tame, while Arctic Monkey groupies flee the building in horror.

But if it is bespoke entertainment that you would like to offer, you could do worse than get together a practice quartet to do requests. Depending on the talent available this might stretch from a cabaret-style piano and singer routine through the inspiring swell of a small brass band to a full-blown production number. The longer the wait, the greater the treat. 'Mrs Harris, we are so sorry to keep you waiting and so it is with enormous pleasure that we present the Smile More Practice's version of Hello Dolly staring Helen the hygienist in the title role.' Never mind waiting time, you'll have them queuing round the block! 